\title{
Recidiva de carcinoma transicional en conducto uretero-ileal tras cistectomía radical
}

\author{
Celma Doménech A, Tremps Velásquez E, Planas Morin J, Bestard Vallejo J, Mir Marisma C, \\ Morote Robles J.
}

Servicio Urología Hospital general de la Vall d'Hebrón. Barcelona.

Actas Urol Esp. 2008;32(6):642-644

\section{RESUMEN}

\section{RECIDIVA DE CARCINOMA TRANSICIONAL EN CONDUCTO URETERO-ILEAL TRAS CISTECTOMÍA RADICAL}

La recidiva de un tumor urotelial en el conducto uretero-ileal tras una cistectomía es poco frecuente, especialmente sin afectación del tracto urinario superior. Presentamos un caso de afectación de la unión uretero-ileal por tumor urotelial en un paciente cistectomiazado desde hacía 5 años por un tumor vesical infiltrante, al cual se le somete a un tratamiento endoscópico de su lesión con buenos resultados a los 13 meses de seguimiento.

Palabras clave: Conducto uretero-ileal. Tumor urotelial. Tratamiento endoscópico.

\section{ABSTRACT \\ TRANSITIONAL CELL CARCINOMA RELAPSE IN URETERO-ILEAL CONDUIT AFTER RADICAL CISTECTOMY}

Transitional cell carcinoma relapse in ileal conduit after radical cistectomy is a rare event, especially without upper urinary tract involvement. We describe a case of uretero-ileal transitional cell tumour five years after cistectomy for invasive urothelial tumour. Patient underwent endoscopic treatment with good results after 13 months of follow-up.

Keywords: Ileal conduit. Urothelium cancer. Endoscopic treatment.

$\mathrm{L}^{\mathrm{a}}$ a utilización del conducto ileal descrito por Bricker en 1950 es la derivación urinaria más común tras practicar una cistectomía radical por tumor vesical infiltrante. La recidiva de un tumor urotelial en el tracto urinario superior tras una cistectomía se presenta aproximadamente en un 3\% de los $\operatorname{casos}^{1}$. Sin embargo la recidiva tumoral en la unión uretero-ileal, especialmente sin implicación ureteral en niveles superiores, es muy poco frecuente.

Presentamos un caso de recidiva de carcinoma transicional en la unión uretero-ileal que se presenta con hematuria monosintomática después de 5 años de la cistoprostatectomía radical.

\section{CASO CLÍNICO}

Paciente varón de 69 años de edad sin alergias medicamentosas conocidas, con antecedentes patológicos de infarto agudo de miocardio de arteria circunfleja requiriendo revascularización, en tratamiento actual con antiagregantes, y cistoprostatectomía radical con derivación urinaria tipo BrickerWallace por tumor vesical infiltrante (pT2a G3 NO MO) hace 5 años manteniéndose libre de enfermedad hasta la actualidad.

El paciente presentó episodios autolimitados de hematuria macroscópica monosintomática con coágulos, por lo que se solicitó analítica sanguínea y Rx abdomen que no mostraron alteraciones. Las prue- 
bas de imagen realizadas: Tomografía Computerizada (TC) abdomino-pélvica, Pielografía endovenosa y urorresonancia; destacaron cambios posquirúrgicos sin evidenciarse lesiones ureterales, ni adenopatías y sin dilatación de sistemas excretores. En la ileoscopia, se apreció una imagen compatible con tumor papilar de aproximadamente un centímetro en la unión uretero-ileal.

El paciente rechazó la propuesta de resección del conducto ileal y la realización de una nueva derivación urinaria, por lo que se le propuso como opción alternativa una resección endoscópica a través del conducto ileal de la lesión tumoral.

La resección endoscópica se llevó a cabo con el material habitual (resector monopolar y glicina). Durante la resección se intentó de forma infructuosa cateterizar los uréteres para evitar posibles obstrucciones derivadas de la manipulación. La resección se llevó a cabo de manera cuidadosa resecando la zona exofítica y electrocoagulando la base tumoral, debido al alto riesgo de perforación derivado de la localización.

El paciente siguió un curso postoperatorio correcto por lo que se decidió su alta hospitalaria a las 24 horas.

La anatomía patológica describió un tumor urotelial de alto grado (G3) con marcada reacción inflamatoria, sin poder determinar la infiltración el la pared (Tx) debido a artefactos por electrocoagulación de la muestra.

El paciente se encuentra a los 13 meses de la resección asintomático y con controles por ileoscopia, TC y citología negativos (Figs. 1 y 2).

\section{DISCUSIÓN}

Las recidivas de tumor urotelial en pacientes portadores de una derivación urinaria tipo Bricker por tumor vesical infiltrante son poco frecuentes. Sin embargo han de ser sospechadas, principalmente cuando el paciente presenta hematuria, ya que es la forma más habitual de manifestación inicial en los casos publicados en la literatura ${ }^{2,3}$, como ha sido en nuestro caso. Una pielonefritis obstructiva puede ser también la forma presentación de un tumor urotelial en el tracto urinario superior o en la unión uretero-ileal ${ }^{4,5}$.

El diagnóstico diferencial se ha de establecer con causas benignas de hematuria como infecciones, litiasis o traumatismos. En cuanto a la pielonefritis

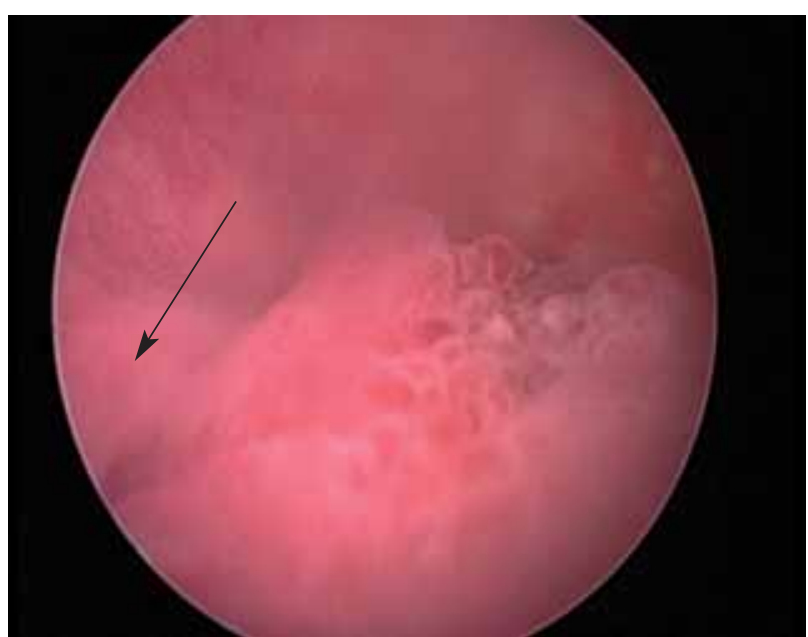

FIGURA 1. Imagen endoscópica del fondo del conducto ileal en la que se aprecia la unión uretero-ileal que marcamos con una flecha y sobre la que protuye un tumor papilar de aproximadamente un centimetro que se aprecia en el centro de la imagen.

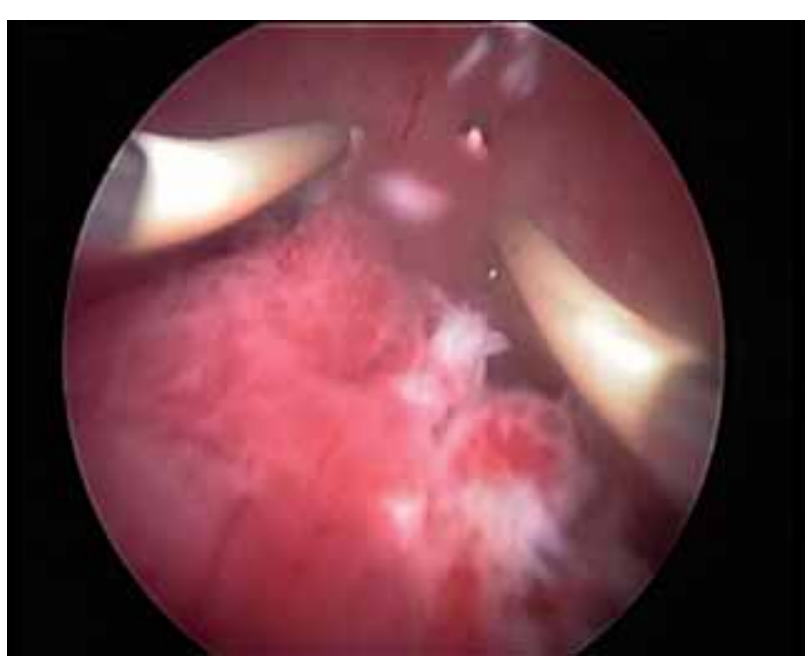

FIGURA 2: Imagen del momento de la resección endoscópica de la lesión tumoral.

los estudios de imagen una vez resuelto el cuadro infeccioso serán los que confirmen que la causa obstructiva es de origen tumoral. Otro diagnóstico diferencial extremadamente raro es la malignización del conducto ileal por el contacto continuado con la orina, en este caso los tumores que se desarrollan con mayor frecuencia son adenocarcinomas ${ }^{6}$.

Para el diagnóstico de estas lesiones las pruebas complementarias de mayor utilidad son la pielografía endovenosa y la TC, aunque en algunos casos como en el que presentamos fue necesaria la práctica de una ileoscopia para poder localizar el tumor. Si bien no es una exploración complementaria de 
rutina, la ileoscopia debería tenerse en cuenta como exploración de segunda línea en caso de pacientes de sospecha de recidiva tumoral que presenten una pielografía o una TC compatibles con la normalidad.

En cuanto al tratamiento endoscópico de este tipo de tumores, hay muy poco descrito en la literatura. Rouprêt ${ }^{7}$ ha publicado recientemente una revisión en la que compara en 97 tumores ureterales la nefroureterectomía, el tratamiento por ureteroscopia y el tratamiento ablativo de forma anterógrada a través de una nefrostomía percutánea, en función del estadio anatomo-patológico y el grado de diferenciación tumoral. Esta revisión concluye que en tumores superficiales de bajo grado no existen diferencias estadísticamente significativas en cuanto a la supervivencia libre de enfermedad a los 5 años y en cuanto a tasa de recidiva entre los diferentes tipos de tratamiento. Sin embargo en los tumores superficiales de alto grado el tratamiento endoscópico presenta una supervivencia libre de enfermedad más baja y una mayor tasa de recidiva con respecto a la nefroureterectomía. Asimismo Rodríguez et al. ${ }^{8}$ describieron ya en 1995 el tratamiento de 18 pacientes afectos de tumores ureterales únicos y de bajo grado de forma endoscópica a través de nefrostomía percutánea o a través de ureteroscopia. Se diagnosticaron 2 recidivas durante el seguimiento de los pacientes (5-84 meses). Estos autores explican que la resección endoscópica puede ser un tratamiento alternativo en pacientes con tumores superficiales de bajo grado con buenos resultados oncológicos.

No se han encontrado datos en la revisión de la literatura referentes al tratamiento endoscópico de tumores de la unión uretero-ileal, ya que en los casos descritos el tratamiento de elección suele ser la resección de la zona afecta y/o la realización de una nueva asa de Bricker ${ }^{5,6}$ o de una ureterostomía cutánea.

La mayoría de autores abogan por el seguimiento de estos pacientes con la realización de pielografías endovenosas y citologías urinarias anuales, aunque también se ha propuesto la realización de ileografías para el seguimiento de estos pacientes ${ }^{9}$.

\section{CONCLUSIONES}

La recidiva tumoral en el conducto ileal de la derivación urinaria es una patología que debe ser sospechada especialmente en pacientes sometidos a cistectomía que presentan hematuria y/o pielonefritis obstructivas, y que las pruebas de imagen no demuestran alteraciones de las vías urinarias superiores.

La resección endoscópica de estas lesiones es un tratamiento alternativo en pacientes de alto riesgo o que rechazan tratamientos radicales.

\section{REFERENCIAS}

1. Zincke H, Garbeff PJ, Beahrs JR. Upper urinary tract transitional cell cancer after radical cystectomy for bladder cancer. Journal of Urology. 1984;131(1):50-52

2. Rosvanis TK, Rohner TJ, Abt AB. Transitional cell carcinoma in an ileal conduit. Cancer. 1989;63(6):1233-1236.

3. Carter A, Gillatt DA. Recurrent transitional cell carcinoma arising within an ileal conduit following cystectomy. A case report and review of the literature. European Urology. 1996;30(4):519520.

4. Shioji Y, Morita T, Tokue A. Transitional Cell Carcinoma in the Ileal Conduit Following Radical Cystectomy and nephroureterectomy. Scand J Urol Nephrol. 2001;35(5):416-417.

5. So A, Hickey L, Norman R. Late ureteral conduit urinary leak as a presentation of urothelial carcinoma of the ureter. Urology. 2002;59(6):946.

6. Ali-El-Dein B, El-Tabey N, Abdel-latif M, Abdel-Rahim M, ElBahnasawy MS. Late uro-ileal cancer alter incorporation of ileum into the urinary tract. The Journal of Urology. 2002;167 (1):84-88.

7. Rouprêt M, Hupertan V, Traxer O, Loison G, Chartier-Kastler E, Conort P, et al. Comparison of open nephrouerterectomy and ureteroscopic and percutaneous management of upper urinary tract transitional cell carcinoma. Urology. 2006;67(6):1181-1187.

8. Rodríguez Rodríguez R, Fernández González I, Galbis Sanjuan F, Fernández Fernández E, Escudero Barrilero A, Lovaco Castellanos F. Definitive endourological treatment in urothelial tumors of the upper urinary tract. Arch Esp Urol. 1995;48(9): 937-943.

9. Noble J, Amin Z, Kessel D, Rickards D. Recurrent upper tract urothelial tumours: the use of loopography following cystectomy for bladder cancer. Brithish Journal of Radiology. 1994;67(803): 1057-1061.

Correspondencia autor: Dra. A. Celma Doménech

Servicio Urología. Hospital general de la Vall d'Hebrón

Passeig de la Vall D’Hebrón, 119-129 - 08035 Barcelona

Tel.: 932746000

E-mail autor: anacelmad@hotmail.com

Información artículo: Nota Clínica

Trabajo recibido: diciembre 2006

Trabajo aceptado: febrero 2007 